\title{
Representaciones sociales \\ de la ciencia y la tecnología
}

\author{
Cristóbal Torres Albero \\ Universidad Autónoma de Madrid \\ cristobal.torres@uam.es
}

RESUMEN

ABSTRACT

Este artículo trata de contribuir a la renovación del enfoque tradicional que el campo de la comprensión pública de la tecnociencia ha aplicado a la así llamada «percepción social de la ciencia y la tecnología». Para ello parte de la noción de representaciones sociales, y pasa revista crítica a los argumentos y evidencia empírica que han conformado sus tres ejes esenciales: mayoritaria apreciación positiva de estos temas en la opinión pública, alto interés hacia los mismos y existencia de un vínculo causal lineal entre el nivel educativo y la aceptación y apoyo otorgado a la tecnociencia. El artículo finaliza sugiriendo un modelo alternativo al tradicional que vincula las distintas representaciones sociales de la ciencia y la tecnología con los diferentes contextos sociales.

Palabras clave: Representaciones Sociales, Ciencia, Tecnología, Percepción Social, Opinión Pública.
This article attempts to renovate the traditional approach that public understanding of the technoscience field has assigned to the so-called «social perception of science and technology». For that reason it takes into account the notion of social representations and makes a critical review of the arguments and empirical evidence that have constituted their three essential main ideas: wide positive evaluation of these subjects in public opinion, a high interest in them, and the existence of a linear causal link between the level of education and the acceptance and support given to technoscience. The article ends by suggesting an alternative model to the traditional approach which links the plurality of social representations of science and technology with the different social contexts.

Keywords: Social Representations, Science, Technology, Social Perception, Public Opinion. 



\section{INTRODUCCIÓN ${ }^{1}$}

La creciente centralidad que han alcanzado la ciencia y la tecnología en las sociedades contemporáneas avanzadas, cuya convergencia e indisoluble vínculo en las mismas puede expresarse con el apócope «tecnociencia», ha llevado consigo el surgimiento de nuevos campos de indagación en el universo de relaciones entre la sociedad y la tecnociencia. Uno de ellos tuvo su arranque en la tradición académica anglosajona que, a ambos lados del Atlántico, comenzó a ocuparse de las formas en que la sociedad conoce, se interesa, entiende y valora la ciencia. Este conjunto de preocupaciones se extendió posteriormente a la dimensión tecnológica. Mientras que en Estados Unidos, al menos en un inicio, el campo se etiquetó como scientific literacy (alfabetización científica), dada su preferencia por estimar cuestiones vinculadas al nivel de conocimiento de los contenidos sustantivos de la ciencia y de la lógica de su proceder (Durant, 1992), en el Reino Unido se acuñó la denominación de public understanding of science (comprensión pública de la ciencia) como opción hacia un enfoque más diversificado y menos centrado en la cuestión de la mayor o menor alfabetización y popularización de la tecnociencia. En los últimos años se ha optado por ofrecer una perspectiva de análisis más amplia, y de superar la limitación de las tesis manejadas por los estudios habituales de la comprensión y alfabetización tecnocientífica, lo que se expresa en que comienza a preferirse el término, proveniente del ámbito de influencia francesa, de cultura científica y tecnológica para la denominación del campo (Godin y Gingras, 2000). Este artículo trata de reforzar este proceso de migración conceptual y, para ello, considero y discuto una de las vetas que han constituido este campo, la que tradicionalmente se ha denominado como «percepción social de la ciencia y la tecnología», dado que, a mi entender, presenta una mayor afinidad con la lógica del análisis sociológico, y que en la misma se encuentra el núcleo fundamental de asunciones teóricas y hallazgos empíricos del enfoque habitual de la comprensión y alfabetización tecnocientífica.

En relación a la cuestión planteada, mi punto de partida es la discusión del concepto teórico clave utilizado como herramienta de indagación, el de percepción social. Mi crítica fundamental es que ésta es una noción más propia de la tradición psicológica que limita las posibilidades metodológicas de la investigación desde el prisma de la sociología. Mi crítica no es corporativa a favor de la disciplina sociológica, dada la fecundidad teórica de las fertilizaciones cruzadas de conceptos que entre campos científicos con cierta afinidad han observado la historia y la sociología de la ciencia (Ben-David, 1964), sino de índole metodológica. Así, el núcleo del planteamiento de este artículo es que los estudios habituales

1 Este artículo forma parte del proyecto de investigación Cultura científica y tecnológica (BSO2001-0171/CPSO), financiado por el Ministerio de Ciencia y Tecnología. Agradezco a Miguel Beltrán, Pedro González Blasco, Rubén Blanco y Manuel Fernández Esquinas su ayuda y comentarios críticos. 
sobre percepción social de la ciencia y la tecnología, y especialmente sobre la ciencia, no han dado cuenta de su imagen real por cuanto que, imbuidos de un afán prescriptivo y cuantificador, han recurrido a un concepto que reducía el problema a su dimensión más individual, y olvidaban el trasfondo social en el que las actitudes individuales surgen y se hacen explícitas. Nuestra tarea como sociólogos es la contraria, es decir, exprimir el enfoque del contexto o medio social en el que esas percepciones individuales se construyen socialmente.

Mi propuesta también sostiene que los hallazgos de los estudios tradicionales de «percepción social» son aprovechables si reorientamos el análisis de sus datos hacia un concepto que se encuentra en la sociología clásica de Émile Durkheim y, especialmente, en su remozamiento en la década de los sesenta por el psicólogo social Serge Moscovici, dado que colectivo y social no son totalmente equivalentes. Sobre la clásica aportación de Durkheim de «representaciones colectivas» (1898) retomó su análisis Moscovici (1984) con el concepto de «representaciones sociales», que permite subrayar los factores sociales de la percepción y, con ello, destacar la importancia que los grupos y sus «normas» tienen sobre la representación de la realidad social. Como ha indicado Ibáñez García (1988), el concepto de representación social no sólo incorpora todas las ventajas heurísticas de conceptos propios de la tradición psicológica, como imágenes, percepciones, actitudes y procesamiento de informaciones, sino que conecta con conceptos sociológicos de más largo alcance conceptual, como normas, valores, culturas o ideologías. Sigo esta senda conceptual sin por ello renunciar a considerar los resultados empíricos obtenidos en el tradicional enfoque de la percepción social de la tecnociencia.

Hasta aquí he fijado el ámbito (el territorio) de análisis, bosquejado muy escuetamente la tradición académica (el mapa disponible) a la que se adscribe el área en cuestión, y establecido el punto de vista (la brújula) con el que acometo este camino. En el resto del artículo desarrollo las siguientes operaciones: en primer lugar, expongo lo que considero son las bases fundamentales de este más amplio campo y, con ello, doy cuenta de los tres ejes que conforman la franja de la «percepción social». Campo que en su conjunto de asunciones e investigaciones ha descansado en lo que se ha etiquetado (Gross, 1994) como un modelo deficitario (deficit model), presidido por lo que con acierto se ha calificado como un cognitivismo ilustrado (Pardo, 2001: 1092). Al introducir una perspectiva longitudinal y comparativa en mi análisis muestro cómo las diversas fuentes disponibles de datos secundarios no permiten sustentar los tres hallazgos esenciales que conforman la aproximación tradicional: la existencia de una mayoritaria apreciación positiva de la tecnociencia en la opinión pública; la presencia de un fuerte interés hacia la ciencia y la tecnología en la ciudadanía, y la identificación de un vínculo lineal entre el grado de instrucción educativa y/o alfabetización tecnocientífica (variable independiente) de los ciudadanos y los niveles de 
aceptación y apoyo (variable dependiente) que otorgan a la tecnociencia. Cada uno de estos puntos se aborda en un epígrafe distinto a través de diverso material empírico disponible: encuestas monográficas sobre esta materia realizadas en España y la Unión Europea (Eurobarómetro) y encuestas no monográficas existentes en el Banco de Datos del CIS. Tras este recorrido planteo un epígrafe final de conclusiones en el que sugiero un modelo alternativo que vincula las distintas representaciones sociales de la tecnociencia con los diferentes rasgos que enmarcan los diversos contextos sociales.

\section{LA TESIS TRADICIONAL DE LA «PERCEPCIÓN SOCIAL» DE LA CIENCIA Y LA TECNOLOGÍA}

Las ideas meliorativas de progreso técnico y moral, abundancia y bienestar han dominado habitualmente la imagen de la ciencia y la tecnología desde el arranque de la Revolución Científica hasta prácticamente el último tercio del siglo xx. Sobre la base histórica de esta concepción pública de la ciencia y la tecnología, y con el trasfondo del contexto social del último tercio del siglo xx, en el que la tecnociencia pasó en los países occidentales desarrollados de un estatus de apoyo y respeto a una creciente contestación y crítica social (Blanco e Iranzo, 2000), arrancan en Estados Unidos a finales de los años cincuenta del siglo pasado, y reanudados y sistematizados desde la década de los setenta, los estudios sobre la alfabetización y comprensión pública de la ciencia y la tecnología. Estudios que, al menos en la primera fase de investigaciones empíricas de este campo, desarrollaron la tesis de que existe una evaluación positiva en la consideración que la ciudadanía tiene de la tecnociencia.

Como he indicado, esta interpretación ha descansado en lo que Gross (1994: 6-9) ha llamado el modelo deficitario, dado que asume la simultánea existencia de un déficit de formación e información en la ciudadanía y de una suficiente capacidad entre los científicos. De esta manera, cualquier crítica o posición desaprobadora que la opinión pública haga sobre la tecnociencia (sus procedimientos, innovaciones, impactos, etc.) se interpreta como una carencia o déficit en el adecuado nivel de conocimiento que debe mantener de estas materias. Por ello se considera conveniente establecer un proceso comunicador en el sentido de arriba abajo en el que los científicos, usualmente a través de los medios de comunicación, rellenen el vacío de noticias y de conocimiento de aquella parte (mayoritaria) del público que se identifica como ignorante, o incluso analfabeta, en términos tecnocientíficos. Se entiende así que un incremento de la actividad divulgativa aumentará la comprensión en estos temas de la ciudadanía, con la consiguiente mejora en el apoyo público a las iniciativas públicas y privadas que se tomen a favor del desarrollo científico y tecnológico. Con ello, el conocimiento y las actitudes son considerados como afectados por la misma lógica, dado que se asume que el aumento de la comprensión generará actitudes más po- 
sitivas. Esto supone la existencia de un público pasivo que necesita de una retórica para acomodar los logros y métodos tecnocientíficos a unas experiencias y capacidades cognitivas limitadas de la ciudadanía, puesto que el valor positivo de la ciencia y la tecnología es la clave no discutida para la conformación de las actitudes meliorativas sobre las mismas. Su corolario es que las cuestiones éticas o políticas vinculadas a la tecnociencia no existen o son colaterales, sus impactos concretos se contemplan como aproblemáticos, y la comunicación tiene sentido en tanto que transmite conocimiento que se traducirá en apoyo y legitimación. La base de este esquema es que no se toma en cuenta la génesis histórica que ha permitido perfilar y atribuir un valor positivo a la ciencia y la tecnología.

Este marco ilustrado se ha concretado en la específica franja de la «percepción social de la ciencia y la tecnología» con una triada de ejes y hallazgos, que aquí he etiquetado como tesis tradicional, y que a continuación refiero en sus aspectos esenciales:

En primer lugar se encuentra la idea de que existe una mayoritaria apreciación positiva de la ciencia y la tecnología entre la opinión pública. Esta valoración se debe al reconocimiento de sus contribuciones al bienestar humano y a su papel en la liberación de la situación de dependencia que se encontraba la humanidad antes de su constitución como una institución social. Institución que, como cuestión de rutina, se encarga de indagar en el mundo y de construir artefactos que contribuyen a remediar un tipo de vida que con anterioridad, en la célebre expresión de Hobbes, resultaba dura, bruta y corta para la especie humana. A lo sumo, y debido al contexto de creciente crítica social de algunos ámbitos concretos de aplicación tecnológica con potenciales posibilidades de alteración del ciclo básico de la naturaleza (como el uso de la energía nuclear o el más reciente de la biotecnología), se reconocía la distancia de la opinión pública con estos campos específicos, de tal manera que tal desafección se entendía como una cautela o reserva ante el potencial efecto devastador que pudiera tener un uso indebido. Algo que, por otra parte, se consideraba ajeno a las reglas morales y profesionales de la comunidad científica. No obstante, en el ámbito de las aplicaciones tecnocientíficas podían ser algo distintas, por lo que la tecnología sería la causante de cualquier desafecto que pudiera surgir en la ciudadanía, mientras que la ciencia mantendría la integridad de la confianza y valoración meliorativa.

El segundo eje de esta tesis clásica se ha configurado sobre el supuesto de la centralidad asignada a la tecnociencia como agente modernizador de las sociedades, dado su decisivo papel en la configuración de nuevas realidades económicas, sociales, culturales, etc., que culminan en la constitución de una sociedad desarrollada y con altos niveles de bienestar. Sobre esta base, los estudios de percepción social de la ciencia y la tecnología han buscado evaluar el grado en el que las opiniones públicas reconocen este papel de la tecnociencia. En este sentido, y acorde con una mayoritaria actitud positiva hacia la tec- 
nociencia, este enfoque ha destacado el alto, cuando no central, interés que la opinión pública concede a la tecnociencia y a su promoción por parte de las políticas públicas, incluso por encima de ámbitos y actividades mucho más familiares y próximos en la vida cotidiana. Así, concluyen que la opinión pública les otorga un destacado interés frente al resto de temas y preocupaciones que tejen el habitus del ciudadano y compiten por atraer su atención y respaldo.

Finalmente, en estrecha conexión con los dos puntos anteriores y como núcleo duro de la tesis tradicional, se afirma con un claro sentido ilustrado que existe un vínculo directo entre los niveles de instrucción educativa y/o alfabetización tecnocientífica y la valoración que se hace de la ciencia y la tecnología. De tal manera que a mayor nivel educativo y/o de alfabetización tecnocientífica, mayor apreciación se hace y mejor actitud se tiene de la ciencia y la tecnología, y de su papel en el desarrollo de las sociedades avanzadas contemporáneas. Y, a sensu contrario, la presencia de valoraciones negativas asociadas al papel de la ciencia y la tecnología se explica por los déficits educativos y de alfabetización de una población que sólo una decidida política de promoción educativa podría corregir a medio y largo plazo.

A mi entender, el perfil específico formado por estos tres ejes tiene que ver con que los estudios habituales de este campo de la comprensión pública de la ciencia han estado dominados por los intereses de las élites científicas y las políticas de las agencias gubernamentales para mejorar su capacidad de comunicación con la más amplia sociedad, siempre con el fin de ganar legitimidad democrática en sus planteamientos y demandas concretas. Por ello, no es de extrañar que el surgimiento de este campo en el último tercio del siglo pasado fuera parejo a la crisis, ya reseñada, de confianza social que la ciencia y la tecnología experimentaron a partir de finales de los años sesenta. De otra parte, no debe desconsiderarse la trascendencia práctica del campo, por cuanto que la crucial impronta de la tecnociencia en la estructura económica, social, cultural y política de las sociedades avanzadas demanda tomar iniciativas que guíen las políticas públicas en esta materia concreta que, en tanto que sociedades democráticas, sean legítimas y estén en sintonía con las preferencias mostradas por la ciudadanía. Las experiencias y estudios ya desarrollados en los distintos países de la Unión Europea y la OCDE, o los que actualmente se inician en otras regiones geopolíticas como Latinoamérica, revelan que estas cuestiones constituyen un asunto relevante dentro de la agenda de las políticas gubernamentales de las naciones desarrolladas.

Pero, asumiendo estas consideraciones sociopolíticas, considero que una de las tareas de la sociología de la ciencia y la tecnología debe consistir en restituir el equilibrio teórico-empírico de este área de problemas, que debe estar presidida por una lógica similar a la que existe en el resto de áreas de las ciencias sociales. En esta línea deben entenderse los da- 
tos empíricos y argumentos que se aportan a continuación, que tratan de poner de manifiesto las diferentes representaciones sociales que existen de la ciencia y la tecnología y que, por tanto, no pueden seguir interpretándose bajo los supuestos del deficit model.

\section{UNA PERSPECTIVA LONGITUDINAL SOBRE LA TESIS DE LA REPRESENTACIÓN MELIORATIVA DE LA TECNOCIENCIA}

Frente a lo que supone la tesis tradicional, los datos de las distintas encuestas que, desde principios de la década de los ochenta, existen sobre el caso español ponen de manifiesto la imposibilidad de seguir asumiendo la afirmación de que existe en España una mayoritaria positiva valoración de la ciencia y la tecnología, al menos cuando se plantea la cuestión en términos generales.

Para sostener esta afirmación he elaborado la tabla 1, donde recojo los datos de trece distintas encuestas, realizadas desde enero de 1982 hasta septiembre-octubre de 2004. De las trece, diez han sido realizadas por el Centro de Investigaciones Sociológicas (CIS), dos por la Fundación Española para la Ciencia y la Tecnología (FECYT) y una por el Centro de Investigaciones de la Realidad Social (CIRES). Del total de encuestas, sólo en tres (números 7,8 y 12) puede señalarse un déficit metodológico en la redacción de la pregunta debido a que su formulación busca estimar el grado de acuerdo sobre uno de los polos de dicotomía «positivo vs. negativo». En estos tres casos concretos se indaga en el grado de acuerdo sobre una afirmación negativa («más problemas que soluciones»; «más mal que bien») respecto de la ciencia moderna. Sin embargo, los datos no son peores que los registrados en las encuestas posteriores en las que la pregunta se planteó en términos equilibrados, es decir, comparando una frase positiva con otra negativa y, en el mejor de los casos, añadiendo una alternativa intermedia que permita evaluar las posiciones equidistantes. De otro lado, y tal y como se especifica en la nota al pie de la referida tabla, seis de las encuestas refieren su pregunta sólo a la ciencia, mientras que en las siete restantes la pregunta incluye el conjunto de ciencia y tecnología. De nuevo, esta diferencia no permite establecer una pauta de evaluación diferente de la que marca el más amplio análisis longitudinal de la totalidad de las encuestas. Es decir, los resultados de las encuestas cuando se considera sólo a la ciencia no son mejores que cuando se pregunta conjuntamente por la ciencia y la tecnología (especialmente manifiesto en la comparación entre las dos encuestas de la FECYT). El análisis, como también se indica en la nota a pie de la referida tabla, se beneficia del hecho de que hasta un total de nueve encuestas han repetido una pregunta idéntica, si bien se trata de cuatro preguntas distintas que se han usado en dos (es el caso de las encuestas identificadas con las letras A, C y D) o tres ocasiones (las encuestas señaladas con la letra B). En todo caso, este conjunto de variaciones no impiden 
que la tabla ofrezca un perfil completo de la evolución de la opinión pública española en la consideración que muestra ante la ciencia y la tecnología en términos generales de sus beneficios o perjuicios para la sociedad.

El primer dato disponible, gracias a una pionera encuesta del CIS realizada en enero de 1982 y dirigida por los profesores García Ferrando y González Blasco, ofrece un dato acorde con el primer punto de la tesis tradicional, dado que casi las dos terceras partes (64\%) de la opinión pública optan por la alternativa positiva, frente a sólo un $8 \%$ que mantiene una negativa apreciación de la misma. Sin embargo, la siguiente encuesta del CIS, efectuada en octubre de 1987, presenta un destacado vuelco dado que las respuestas positivas descienden por debajo de la mitad de la ciudadanía (42\%), mientras que las respuestas negativas se doblan (15\%) y las posiciones equidistantes llegan a la tercera parte (31\%) del total poblacional. Este muy significativo cambio puede explicarse, en mi opinión, por el impacto en la opinión pública del accidente de la central nuclear de Chernobil, acaecido a finales de abril de 1986. A mi entender, «el pecado original» de la energía nuclear (Hiroshima y Nagasaki) despertó de súbito en la memoria colectiva de la ciudadanía, dado que entendió que se cumplían los peores vaticinios que los movimientos ecologistas venían anunciando respecto del riesgo que, para el medio ambiente y la vida, suponen los avances tecnocientíficos en general, y el recurso a la energía nuclear en particular.

Sin embargo, un quinquenio después (febrero de 1992) los datos de la encuesta del CIRES muestran una sorprendente recuperación, puesto que el dato positivo, para el conjunto ciencia y tecnología, se situaba en el $69 \%$ de la ciudadanía española. Pero, a mi juicio, el siguiente registro ofrecido en junio de 1994 por el CIS ofrece un dato más fiable, no sólo porque las respuestas positivas $(52,9 \%)$ se sitúan en la banda habitual de los resultados obtenidos en buena parte de las posteriores encuestas del CIS. También porque, dada la estabilidad de las respuestas negativas y del No sabe/No contesta entre esta encuesta del CIS y la del CIRES, la diferencia puede deberse a la distinta redacción de las preguntas, mucha más fina en la encuesta del CIS dado que abre una tercera variante de respuesta, siquiera espontánea, que permite recoger las opiniones intermedias («un poco de cada») del continuum positivo vs. negativo. Así, la suma de los datos de la opción intermedia («ni acuerdo, ni desacuerdo") y de la afirmación meliorativa es coincidente con el porcentaje de afirmaciones positivas registradas en la encuesta del CIRES.

Pero las dos siguientes encuestas realizadas (números 5 y 6) muestran, de nuevo, un abrupto descenso de las valoraciones positivas respecto de la consideración de la ciencia y la tecnología. Incluso en la encuesta de marzo de 1997 se produce la primera y única inflexión, dado que la opinión meliorativa $(29,2 \%)$ se sitúa muy significativamente por debajo de las consideraciones negativas (38\%). Al respecto, mi interpretación sostiene que el im- 
pacto que en la opinión pública tuvieron las noticias de la llamada «enfermedad de las vacas locas» que, procedentes del Reino Unido, comenzaron a aparecer en los medios de comunicación de masas a partir de marzo de 1996, y que fueron creciendo a lo largo de 1997, constituye el locus explicativo de este abrupto descenso de la apreciación positiva y del súbito aumento de la consideración negativa. Pero, tras la saturación informativa y final (mediático) de dicha crisis, los datos obtenidos comienzan a estabilizarse y situarse en la línea de los resultados de la encuesta del CIS de junio de 1994. Y, así, la franja en la que se mueven los porcentajes que registran las opiniones positivas se sitúa entre el $57,2 \%$ (junio de 2000) y el 48,6\% (marzo-abril de 2001), siendo el último dato ofrecido por el CIS (febrero-marzo de 2004 ) de un $50,9 \%$.

Finalmente, las dos encuestas monográficas de la FECYT, realizadas en septiembre-octubre de 2002 y 2004 a una población de 15 y más años, muestran datos muy estables al revelar que las opiniones positivas respecto de la ciencia y la tecnología se sitúan en torno al $47 \%$. Además, y frente a lo que pudiera sostener la tesis tradicional, no se observa una diferencia en las respuestas en función de si en la redacción de la pregunta se incluye sólo a la ciencia (2002) o a la ciencia y la tecnología (2004). De otro lado, la finura de la redacción de la pregunta, más cuidada que en las encuestas del CIS en lo referido a la identificación de un posicionamiento equidistante en la dicotomía «positivo vs. negativo», permite afirmar que una tercera parte de la opinión pública prefiere esta alternativa intermedia, amén de que una décima parte se decanta por un juicio negativo, y algo menos (7,6\%) opta por el No sabe/No contesta.

En suma, la perspectiva longitudinal que ofrece la tabla 1 permite afirmar que en los últimos veintitrés años se ha producido en España un significativo descenso en las actitudes meliorativas ante la ciencia y la tecnología consideradas en términos generales. Caída que oscila entre los 17 (máximo) y los 13 (mínimo) puntos según se tomen, respectivamente, las últimas encuestas de la FECYT o del CIS. Los datos más recientes, válidos y fiables (FECYT, 2004) indican que, de manera aproximada, sólo la mitad de la ciudadanía opta por una consideración positiva de las mismas, mientras que la otra mitad se divide entre quienes muestran un punto de vista negativo (alrededor de la décima parte del total), aquellos que mantienen una posición equidistante o ambivalente en la consideración de pros y contras de la tecnociencia (en torno a una tercera parte del conjunto poblacional), y los que refieren indiferencia o desconocimiento (algo menos de la décima parte).

Más allá de la concreción cuantificadora que ofrece esta tabla, también puede concluirse que los dientes de sierra que muestra se ligan a los impactos mediáticos de crisis tan relevantes como la de Chernobil o la de las «vacas locas» en particular, así como a la creciente exigencia de seguridad frente al riesgo de catástrofe medioambiental o biológica que en 


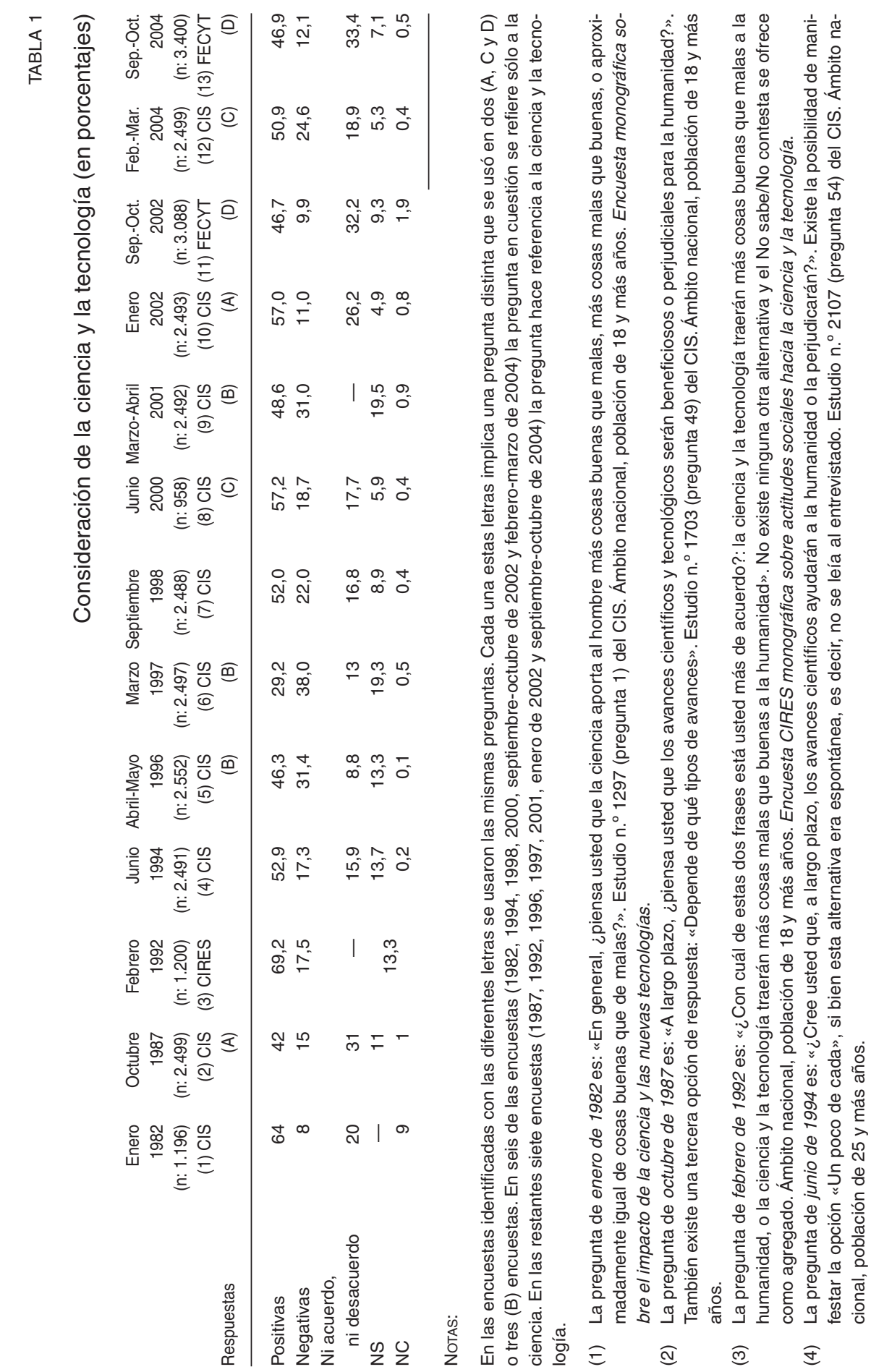




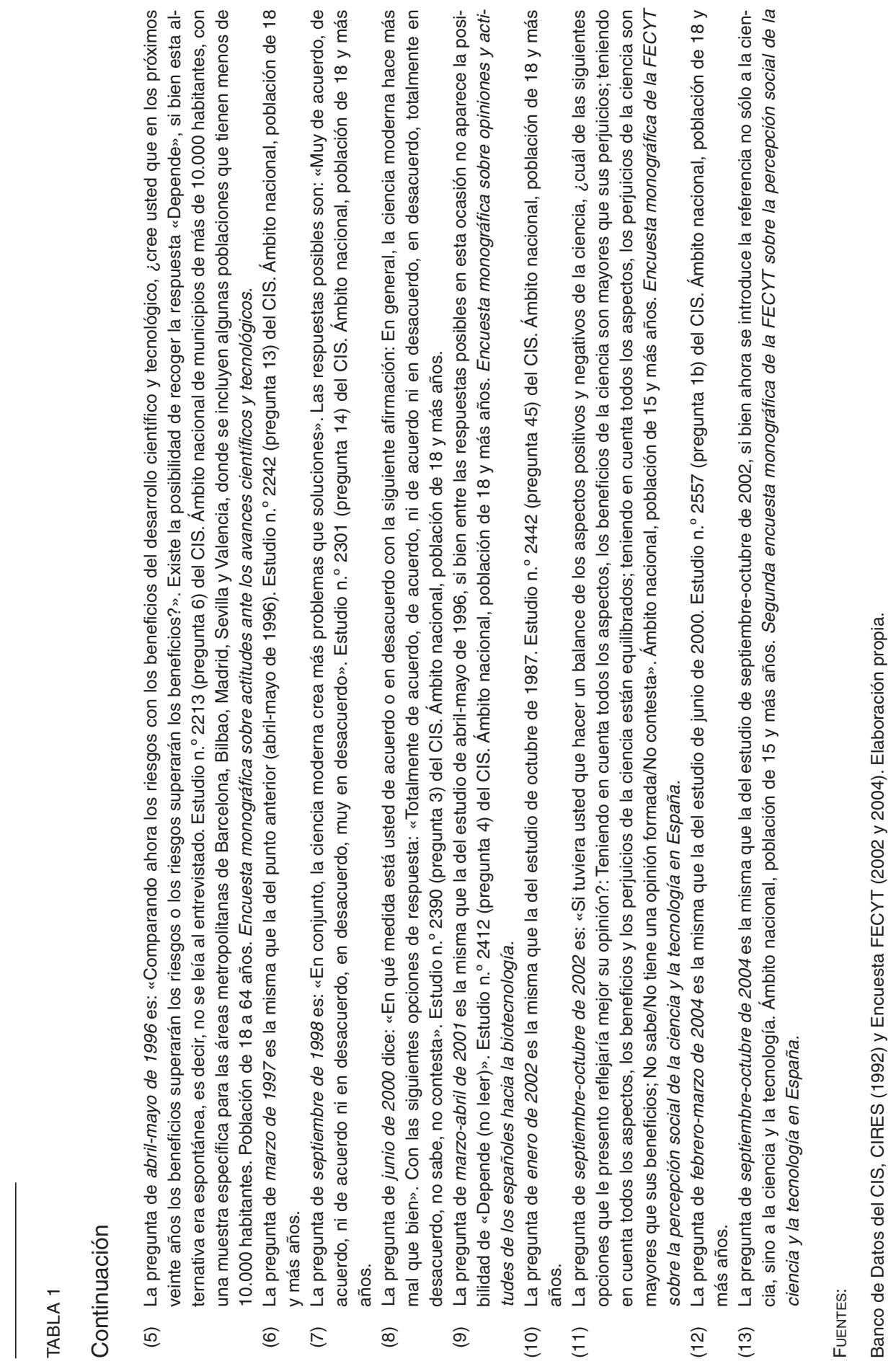


general demanda la ciudadanía de las sociedades desarrolladas. Lo cual permite corroborar la afirmación de Pardo (2001: 1103) de que en la aproximación cultural al estudio de la tecnociencia las coordenadas espacio-temporales cuentan, aun cuando entiendo que también refuta, al menos para nuestro país, la tesis de la existencia en la gran mayoría de la población de actitudes ante la ciencia y la tecnología globalmente positivas.

Los datos registrados en España son consistentes con los que ofrecen los distintos Eurobarómetros sobre la ciencia y la tecnología, acometidos desde una perspectiva propia de los estudios de comprensión pública de la tecnociencia y la alfabetización científica. En concreto, en la tabla 2 se ofrecen los resultados de una pregunta concreta de los Eurobarómetros monográficos sobre ciencia y tecnología realizados en 1992 y 2005, y referida también a la evaluación en términos generales de la ciencia y la tecnología. A pesar del sesgo con el que se ha construido la pregunta, a favor de la opción positiva, y del incremento de la heterogeneidad societal derivada del aumento del número de países integrados en la UE, los resultados globales son grosso modo coincidentes con el balance que sugería el estudio detallado del caso español².

A partir del análisis de diversos ítems utilizados en el Eurobarómetro de 1992, y otros estudios similares desarrollados en similares encuestas sobre comprensión pública de la cien-

TABLA 2

Respuestas a la pregunta del Eurobarómetro (en porcentajes) «Las ventajas de la ciencia son mayores que todos los efectos perjudiciales que pueda tener»

FUENTES:

Eurobarómetros 38.1 (p. 74 del documento editado) y 63.1 (anexo estadístico de resultados a la pregunta $13 . b .3$ en el documento editado). El primero se realizó, en noviembre de 1992, en los 12 países que entonces integraban la Unión Europea. El último se ha llevado a cabo, en enero-febrero de 2005, en los 25 que actualmente la conforman. En ambos casos el universo fueron ciudadanos de 15 y más años.

\footnotetext{
2 El análisis de los datos recogidos en los Eurobarómetros se ve gravemente restringido a nivel nacional por la lógica de segmentación muestral con la que se han aplicado algunas de las preguntas del cuestionario (incluida la que figura en la tabla 2). En el caso español, el total muestral para esta pregunta fue de 513 entrevistas, por lo que no las incluí en la tabla 1.
} 
cia y la tecnología acometidas en Estados Unidos (1995), Japón (1991) y Canadá (1989), J. D. Miller, Pardo y Niwa (1998: 102-124), y con la base de un sofisticado análisis estadístico y la cautela en el análisis de los resultados, han construido sendos índices de confianza y de reserva ante la ciencia. Aun cuando considero que es discutible la validez del constructo, dado que las frases disponibles en los cuestionarios no reflejan los aspectos concretos que conforman la dimensión crítica y ambivalente que asume una parte de la ciudadanía ante la tecnociencia ${ }^{3}$, los autores han concluido (tabla 3 ) afirmando que los canadienses, europeos y japoneses tienen niveles medio-alto de reserva ante las consecuencias negativas reales y potenciales de la ciencia y la tecnología, aun cuando también mantienen que una mayoría sustancial de europeos y norteamericanos mantienen una actitud positiva ante la ciencia y la tecnología, como reflejo de los logros del pasado.

Con todo, la evidencia empírica y los argumentos que he aportado en un reciente artículo (Torres, 2005) permiten, a mi juicio, sostener que el deterioro de las representaciones sociales meliorativas de la ciencia y la tecnología aquí registrado (tabla 1) se debe al creciente aumento de la ambivalencia que, en la conformación de las mismas, presentan las sociedades contemporáneas avanzadas. Especialmente, este hecho se pone de manifiesto cuando el análisis se concreta en la diversidad de campos en los que los desarrollos e innovaciones tecnocientíficos tienen impactos determinados y diferentes. Pero esta tesis de la ambivalencia es compatible con una opinión manifiesta sobre la ciencia y la tecnología considerada en términos generales que, en un contexto dado, puede orientarse mayoritariamente tanto en un sentido meliorativo como en una línea crítica, dado que las actitudes positivas vs. negativas deben interpretarse no como dos ejes incompatibles y alejados, sino a partir de un continuum de posiciones. Continuum que se ve afectado, de un lado, por el hecho de que en una parte significativa de la opinión pública existe una falta notable de consistencia y estabilidad actitudinal (Pardo y Calvo, 2001) y, de otro, porque el conjunto de la ciudadanía forma parte de unas sociedades avanzadas que son a la par, y cada vez en mayor medida, dependientes y exigentes respecto de las aplicaciones y resultados concretos de la tecnociencia (Torres, 2005).

De hecho, si estas tesis de la ambivalencia como concreción del continuum de actitudes no han tenido un mayor despegue previo se debe a que los estudios habituales del campo de la comprensión pública de la ciencia y la tecnología han recurrido, imbuidos de la hegemonía del modelo deficitario, a métodos y técnicas de investigación insensibles a la variabilidad y devenir histórico del contexto social en el que las representaciones sociales se construyen. Así, y como han demostrado Pardo y Calvo (2001: 166 y ss.), el cuestionario utilizado en el Eurobarómetro de 1992, que sigue en lo básico la pauta metodológica y téc-

3 El propio Pardo, junto con Calvo (2001), han puesto de manifiesto la falta de validez de constructo del referido Eurobarómetro de 1992. 


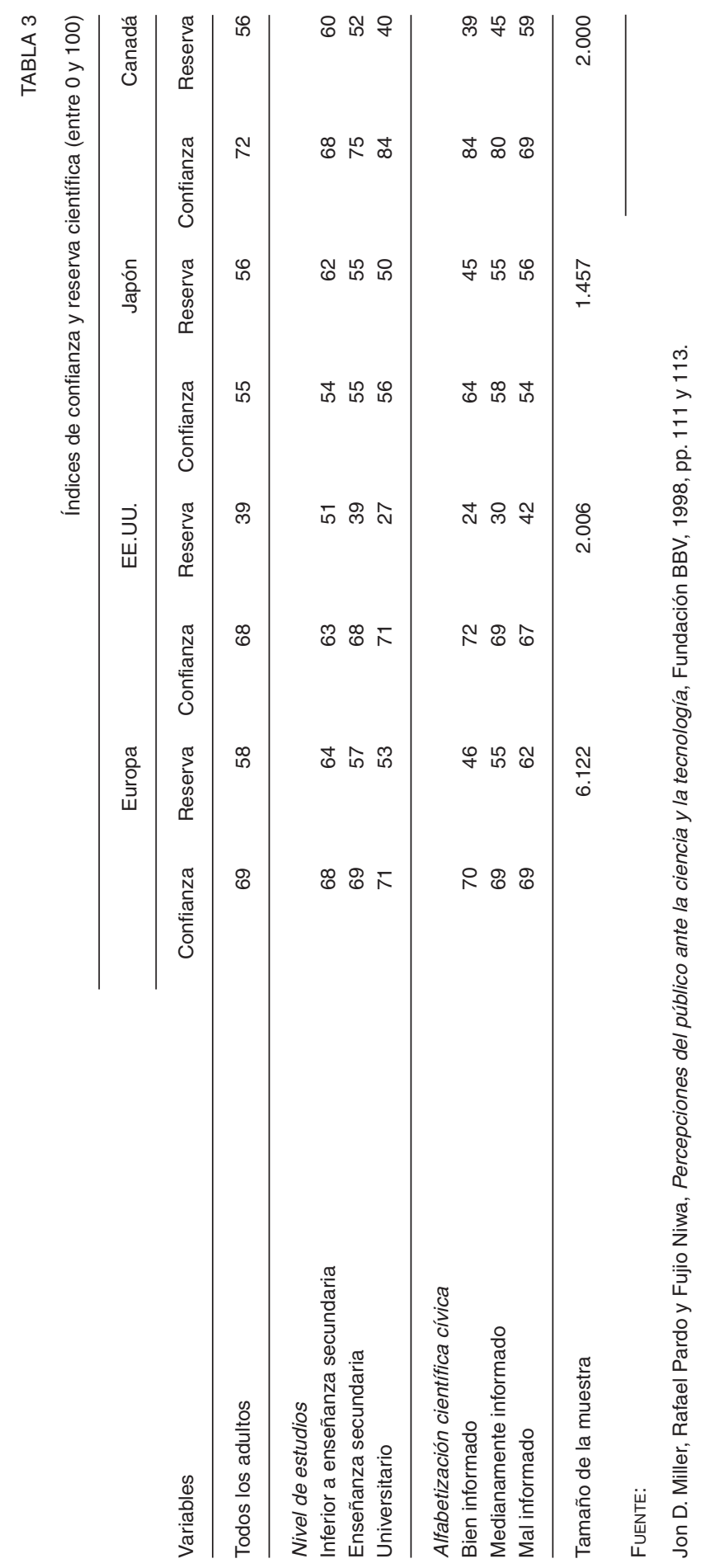


nica de los estudios habituales del campo de la compresión pública de la tecnociencia, carece de los estándares de validez y fiabilidad que son usuales en otras áreas concretas de la investigación en ciencias sociales. Pero, a pesar de la dificultad metodológica que supone la estrecha rejilla de los cuestionarios orientados bajo los estrictos supuestos ilustrados de este hegemónico modelo, la realidad social se ha acabado colando con una evidencia empírica que no permite seguir sosteniendo el primer eje de la tesis tradicional: que la gran mayoría de la población de las sociedades desarrolladas, al menos la española y la del resto de países europeos más desarrollados, mantiene actitudes positivas ante la ciencia y la tecnología en su conjunto.

\section{EL INTERÉS POR LA TECNOCIENCIA EN LA OPINIÓN PÚBLICA}

En lo que respecta al segundo eje sobre el que se ha establecido la tesis tradicional en los estudios sobre «percepción social» de la ciencia y la tecnología, las encuestas monográficas acometidas bajo la perspectiva de la comprensión pública de la tecnociencia suelen concluir refiriendo el destacado interés que la opinión pública concede a los temas de ciencia y tecnología, en consonancia con el crucial papel que este vector tiene en las sociedades avanzadas. Así, por ejemplo, el propio análisis de Miller, Pardo y Niwa referido en el epígrafe anterior pone de manifiesto este aspecto. En la tabla 4 puede apreciarse la destacada declaración de interés que, en términos comparativos frente a otras temáticas, las opiniones públicas de los distintos países y áreas geopolíticas considerados conceden a la ciencia y la tecnología. A tenor de estos datos, este interés está significativamente por encima de la política o los deportes. Incluso cuando se concreta en el ítem «nuevos descubrimientos médicos» (un campo a mitad de camino entre la ciencia y la tecnología, y muy ligado a las preocupaciones cotidianas), la distancia sobre estos últimos dos temas crece notablemente. No obstante, cabe también reseñar que las cuestiones del medio ambiente sobresalen como principal campo de interés declarado de la opinión pública en Europa y Japón, lo cual sugiere una inicial pista acerca de la tensión que sobre las actitudes hacia la tecnociencia acaban generando las preocupaciones medioambientales.

Similar pauta puede establecerse para el caso español a partir de la explotación de los datos obtenidos en la encuesta monográfica sobre actitudes sociales hacia la ciencia y la tecnología que realizó el CIRES en 1992. Mediante la escrupulosa construcción de un índice de interés declarado, González Blasco (1993) ha destacado el interés que los españoles mostraban por los descubrimientos científicos, los inventos y las nuevas tecnologías, muy cercano al que sentían por los descubrimientos médicos (que registraba el índice más alto) y muy por encima del interés declarado por las cuestiones de actualidad deportiva o política, tal y como se aprecia en la tabla 5. 
Puntuación media del índice de interés (entre 0 y 10)

\begin{tabular}{lcccc}
\cline { 2 - 4 } Área temática & Europa & EE.UU. & Japón & Canadá \\
\hline Nuevos descubrimientos científicos & 61 & 66 & 50 & 63 \\
Nuevos inventos y tecnologías & 59 & 66 & 53 & 58 \\
Nuevos descubrimientos médicos & 68 & 82 & 65 & 77 \\
Temas medioambientales & 75 & 73 & 71 & 74 \\
Política & 55 & - & - & 50 \\
Deportes & 48 & - & - & 42
\end{tabular}

FUENTE:

Jon D. Miller, Rafael Pardo y Fujio Niwa, Percepciones del público ante la ciencia y la tecnología, Fundación BBV, 1998, p. 35.

Cuestiones de actualidad

Actualidad deportiva

Actualidad política

Descubrimientos médicos

Inventos/Nuevas tecnologías

Descubrimientos científicos recientes

FuENTE:

González Blasco (1993: 246)
Índices de interés (entre +1 —máximo-y 0 —mínimo-)

Pero con la formulación de este tipo de preguntas comparativas en las que se propone una lista sugerida de cuestiones se corre un riesgo metodológico, dado que puede producirse un sesgo declarativo a favor de las respuestas que los entrevistados asuman, siquiera tácitamente, como socialmente deseables o aceptables, especialmente cuando ante la cuestión no se tiene una posición nítidamente definida (Clark y Schober, 1992). Este riesgo se incrementa cuando el contexto de la recogida de la información es el de una encuesta monográfica, en la que se solicita al entrevistado una declaración de su grado de interés sobre un tema en cuestión y frente a otras cuestiones bien diferentes. Por ello, las encuestas monográficas debieran extremar las cautelas metodológicas ante este tipo de preguntas, tal como ha hecho la más reciente de la FECYT (2004). Una manera de tomar alguna cautela metodológica ante este potencial sesgo declarativo consiste en cotejar esta información con los, también declarados, niveles y tipos de información que los entrevistados dicen recibir de los medios de comunicación. Es un procedimiento habitual de las encuestas mono- 
gráficas encuadradas en el campo de la comprensión pública de la tecnociencia que, no obstante, les ha llevado a éstas a concluir no tanto con una reflexión sobre el sesgo señalado, sino destacando la existencia de un significativo déficit informativo en los temas de ciencia y tecnología entre la ciudadanía.

Otra forma alternativa de reforzar los controles metodológicos consiste en recurrir a aquellas encuestas que, sin estar dirigidas específicamente a indagar en el campo de la percepción social de la ciencia y la tecnología, cuenten con alguna pregunta en la que, junto al interés o atención prestada a este tema, se incluyan otras cuestiones de la vida social, política o económica. En el Banco de Datos del CIS he localizado algunas de ellas. Aquí doy cuenta de dos. La primera realizada en 1984, en unos años en que la ciencia gozaba de una mayoritaria apreciación positiva, tal y como pone de relieve la encuesta del CIS de 1982 reflejada en la tabla 1. La segunda de 1992, es decir, en el mismo año de realización de las dos encuestas arriba mencionadas y que mostraban tan altas autodeclaraciones de interés hacia la tecnociencia.

Los datos de la encuesta de 1984 del $\mathrm{CIS}^{4}$ muestran que sólo un 8,6\% de los españoles manifestaban estar muy interesados en la ciencia y la tecnología, situándose en la banda más baja de porcentajes que se registraron en esta categoría del mayor interés concedido a las distintas cuestiones. Por el contrario, los temas del medio ambiente, la protección de la naturaleza y la ecología (19\%) o los grandes problemas sociales (17,2\%) doblaban esta declaración de estar muy interesados. De otro lado, si se consideran los temas que más desinterés obtenían, resulta que el ítem que nos ocupa se caracterizaba por situarse en el grupo que registraba las frecuencias más altas, junto a la vida política internacional, la política nacional o las formas en que viven las gentes de otros países de Europa. En concreto, casi una tercera parte $(31,5 \%)$ de los encuestados decían estar poco interesados, y casi otra cuarta parte $(23,6 \%)$ referían estar nada interesados en la ciencia y la tecnología.

En mayo de 1992, otra encuesta del CIS indagó en los problemas que más preocupaban a los españoles. Para ello se planteó una lista cerrada de nueve cuestiones, todas ellas sensibles para la opinión pública, y se permitió a los encuestados la posibilidad de mencionar hasta tres respuestas ${ }^{5}$. Los resultados obtenidos muestran que la cuestión de la tecnología atrasada fue señalada sólo por uno de cada diez entrevistados $(9,6 \%)$, y ocupó la última

\footnotetext{
${ }^{4}$ Estudio n. ${ }^{\circ} 1436$ del Banco de Datos del CIS. Ámbito nacional, 18 y más años. Pregunta 1. Trabajo de campo en octubre de 1984.

5 Estudio n. 2007 del Banco de Datos del CIS. Ámbito nacional, 18 y más años. Pregunta 4. Trabajo de campo en mayo de 1992.
} 
posición en el nivel de preocupación. La primera fue el paro $(91,8 \%)$ y, por ejemplo, el ítem de «la situación de la agricultura» fue suscrito por más de la cuarta parte de los encuestados $(27,2 \%)$.

A tenor de esta evidencia empírica, limitada pero significativa, es difícil seguir sosteniendo que la opinión pública española concedía en esos años una centralidad o interés destacado a la tecnociencia dentro de sus preocupaciones cotidianas, más allá de las distintas crisis (dimensión negativa) de tipo Chernobil o «vacas locas», o de los avances (dimensión positiva) en la lucha contra el cáncer o el sida, que han difundido puntualmente los mass media a lo largo de estos años.

Algo que, a mi entender, también puede afirmarse para el momento presente dados los resultados que arroja la encuesta 2004 de la FECYT, que también ha indagado en esta cuestión a partir, entre otras vías, de una mención espontánea y no sugerida de los temas por los que la opinión pública se siente especialmente interesada. Los resultados obtenidos (tabla 6) muestran cómo las cuestiones de medicina y salud (23\%) son las únicas que, por su cercanía a los temas de tecnociencia, destacan sobremanera, aunque por debajo de los deportes (29\%). Las referencias concretas a la ciencia y la tecnología sólo son mencionadas por el 7\% de los entrevistados, ocupando la posición 13 de un total de 19 ítems identificados, y por debajo del interés declarado sobre las cuestiones de alimentación y consumo (15\%) o medio ambiente y ecología (11\%).

El dato obtenido en esta encuesta FECYT para el caso español está en la consonancia con el dato que J. D. Miller, Pardo y Niwa (1998: 86) aportan en la cuantificación del público atento en Europa: una décima parte del total de la ciudadanía. Pero ésta es una categoría más restringida que la del público interesado, puesto que no sólo supone interés, sino que además implica estar muy bien informados y leer regularmente periódicos y revistas de divulgación. De hecho, estos autores estiman que el público interesado, quienes dicen tener un alto grado de interés por estos temas a pesar de creer que no están bien informados, alcanza a una tercera parte del total de europeos. La suma de ambos colectivos supondría un público «afín» a la sensibilidad tecnocientífica de un $43 \%$ del total de la ciudadanía europea en 1992. Pero a partir de la evidencia que, usando una lógica comparativa, he aportado para el caso español, mi consideración es que el interés declarado en las encuestas acometidas bajo la perspectiva de la comprensión pública de la tecnociencia no coincide con el interés real, salvo en el caso del etiquetado como público atento. No obstante, la limitada y fragmentaria evidencia cuantitativa manejada hasta aquí sólo nos permite esbozar esta interpretación como sugerencia de indagaciones futuras que debieran seguir trabajando por avanzar en esta interpretación. 
TABLA 6

«A diario recibimos información y noticias sobre temas muy diversos.

Dígame, por favor, tres temas sobre los que se sienta especialmente interesado" (Multirrespuesta, máximo tres respuestas espontáneas) (en porcentajes)

\section{Deportes}

Cine y espectáculos

Alimentación y consumo

Medio ambiente y ecología $\quad 10,8$

$\begin{array}{ll}\text { Economía } & 8,7\end{array}$

$\begin{array}{lr}\text { Viajes y turismo } & 8,0\end{array}$

Ciencia y tecnología $\quad 6,9$

Vida de famosos $\quad 5,4$

Trabajo/paro/pensiones $\quad 1,7$

Temas de sociedad $\quad 1,4$

$\begin{array}{ll}\text { Noticias de actualidad } & 1,3\end{array}$

Astrología y ocultismo $\quad 1,2$

Otros $\quad 3,3$

Ninguno $\quad 0,5$

No sabe $\quad 6,6$

No contesta $\quad 0,5$

FUENTE:

FECYT, Percepción social de la ciencia y la tecnología en España 2004, p. 276.

En esta línea de enriquecimiento empírico puedo aportar que, en un estudio cualitativo sobre estos mismos temas que he desarrollado mediante ocho reuniones de grupo ${ }^{6}$, comprobé cómo las declaraciones de interés hacia los temas científicos y tecnológicos surgían fácilmente, entre buena parte de los miembros del grupo que estaban poco o nada familiarizados cotidianamente con los temas tecnocientíficos, en cuanto el moderador pedía a los participantes una reflexión sobre la situación de esta cuestión en la sociedad española. El discurso que se generó en estos casos constaba de la siguiente secuencia de puntos argumentales: a) la escasa información disponible sobre estos temas; b) un diagnóstico negativo de la situación de la ciencia y la tecnología en España; c) la conveniencia

6 Diseñadas a partir de la dicotomización de cuatro variables sociodemográficas (estudios, ideología, edad y ocupación). Para los detalles técnicos de este diseño de investigación cualitativo mediante las reuniones de grupo, véase Torres (2005). 
de prestar mayor apoyo a estas fuerzas y, con ello, d) la declaración de un interés explícito en esta materia, y e) la demanda para mejorar el nivel de información y conocimiento en las mismas, que se asume casi con un sentimiento de culpa. Sin duda, este tipo de discurso se ajusta a los supuestos del deficit model. En todo caso, estimo que esta cadena discursiva puede interpretarse mejor como un interés por sublimación que surge como compensación del déficit científico y tecnológico presente en una parte significativa de la sociedad española que, de otra, apuesta por estas materias para tratar de alcanzar los niveles de desarrollo y bienestar de los países más avanzados de nuestro entorno. Así, a partir de que los discursos de los grupos se adentraban en otros vericuetos, como la consideración de pros y contras de aplicaciones tecnocientíficas concretas, o las prioridades de los problemas del país, la cuestión desaparecía de los nodos de los discursos generados. Es por esto por lo que considero que se trata, más bien, de un interés retórico que de un vector que estructura las pautas de atención informativa de la ciudadanía.

Una línea interpretativa cercana a esta hipótesis ha sido sugerida a partir de los análisis de los Eurobarómetros dedicados monográficamente a la ciencia y la tecnología que se realizaron en 1989 (Bauer, Durant y Evans, 1994) y 1992 (Durant, Bauer, Gaskell, Midden, Liakopoulos y Scholten, 2000). Estos autores han comparado los distintos datos registrados de interés declarado ante esta cuestión en los países de la UE, que presentan niveles de industrialización y desarrollo distintos, y han concluido que existen formas e intensidades de expresar interés y desinterés hacia la ciencia y la tecnología mucho más complejas que la prevista por el modelo deficitario. Así, existían formas de desinterés (relativo respecto al resto de países comparados) por atraso o desconocimiento de la impronta tecnocientífica, como en Portugal o Irlanda, tal como supone el referido modelo. Pero también existe un desinterés declarado por estrecha cercanía y familiaridad histórica con la tecnociencia, especialmente en Alemania y Dinamarca. Algo que no contempla dicho modelo. De otra parte, el (comparativo) mayor interés puede deberse a la proximidad y mayor nivel de conocimiento con esta materia, como ocurre, tal y como afirmaría el modelo, en Francia y Holanda. A esta triada de posibilidades cabe añadir, en mi opinión, y en sintonía con el hallazgo referido en las reuniones de grupo, que el incremento de interés registrado en el Eurobarómetro de 1992 en Grecia, y en menor medida también en España, puede deberse a una nueva forma de interés no supuesta por la tesis tradicional. Se trata del interés que surge como sublimación o expresión de la esperanza positiva que para el progreso, bienestar y desarrollo de una colectividad se asigna a la ciencia y la tecnología. Es un interés retórico que, no obstante, permite a los estudios tradicionales del campo de la comprensión pública reforzar la tesis de una «percepción social» meliorativa de la tecnociencia en nuestras sociedades desarrolladas.

Por tanto, este conjunto de hallazgos apuntan la sugerente pista que el interés o desinterés concedido a la ciencia y la tecnología no responde a un modelo lineal que sólo tiene que 
ver con el nivel de conocimiento (el grado de instrucción educativa o la alfabetización tecnocientífica), tal como cabría esperar de los supuestos del modelo deficitario (deficit model). Por el contrario, puede también adoptar conformaciones paradójicas en función de variables tales como el grado de industrialización de un país, la experiencia histórica que la ciudadanía tiene sobre este vector, la familiaridad del marco cultural de cada sociedad con la ciencia y la tecnología, o los debates públicos que los principales agentes sociales han impulsado en una coyuntura concreta. Esta reflexión lleva directamente al tercer eje de la tesis tradicional, su verdadero núcleo y el que más directamente se vincula con el corazón ilustrado que da vida a la misma.

\section{EL VÍNCULO ENTRE CONOCIMIENTO Y ACTITUDES ANTE LA CIENCIA Y LA TECNOLOGÍA}

El hecho de que un incremento en los niveles de instrucción educativa en general, y de alfabetización científica en particular, implique un aumento de los sentimientos positivos hacia la ciencia fue uno de los primeros hallazgos de los estudios pioneros dedicados a evaluar el grado de apreciación de la ciencia en las sociedades avanzadas. Etzioni y Nunn (1974), en un artículo que repasaba la por entonces fragmentaria evidencia empírica disponible en el estudio de la percepción social de la ciencia y la tecnología en Estados Unidos, concluyeron que la variable educativa constituía el mejor predictor para dar cuenta de la confianza en los científicos y de los sentimientos positivos hacia la ciencia. Por el contrario, aquellos con bajos niveles educativos eran quienes más tendían a mostrar una consideración menos favorable de la ciencia. La explicación que proporcionaron fue que las personas más instruidas tienen un mayor conocimiento de la ciencia y, por ello, generan actitudes más positivas hacia la misma. $A$ sensu contrario, el desconocimiento produce más reservas o desconfianza ante sus hipotéticos resultados o las repercusiones concretas.

La asunción de esta tesis ha constituido la clave de bóveda del surgimiento de los estudios e iniciativas de la comprensión pública de la ciencia, así como del establecimiento del modelo teórico (deficit model) que ha dotado de sentido a este campo. En este sentido hay que tener en cuenta que el informe Bodmer (1985), el primero que se elaboró en el Reino Unido sobre esta problemática, hizo frente a las preocupaciones de los científicos de que la fuerte influencia de los medios de comunicación en la opinión pública pudiera hacer políticamente vulnerables los fondos destinados a la investigación científica, estableciendo que la popularización de la ciencia era el mejor antídoto para combatir esta posibilidad. Es decir, que sólo la ignorancia del público constituía un peligro real para el progreso de las actividades científicas y tecnológicas, y que cualquier aumento de la alfabetización científica mejoraría su valoración social. De hecho, en 1988 se realizó en Gran Bretaña la primera 
encuesta bajo la lógica de la comprensión pública de la ciencia y arrojó unos resultados similares a los que desde los años setenta se habían obtenido en Estados Unidos. A saber, que sólo una décima parte o menos de la ciudadanía, según la distinta definición que se usara, era alfabeta en términos científicos, aun cuando más de las tres cuartas partes declaraban estar interesadas en estos temas. Había, por tanto, un amplio margen para las iniciativas públicas y privadas que contribuyesen a mejorar esta situación, y para las actividades de diagnóstico empírico y de evaluación de los progresos que en los distintos parámetros (alfabetización, interés, actitudes, apoyo de las políticas públicas, etc.) pudieran producirse (S. Miller, 2001).

En el estudio comparativo de J. D. Miller, Pardo y Niwa (1998) ya referido, los autores encontraron en los cuatro ámbitos geopolíticos considerados que la evaluación positiva ante la tecnociencia es mayor entre los ciudadanos con un nivel educativo universitario y menor entre quienes abandonaron los estudios antes de acabar la enseñanza secundaria. Pero también es reseñable que los datos sólo eran estadísticamente significativos en Canadá. De otro lado, al considerar lo que la tesis tradicional asume como una variable más fina, la alfabetización científica, resulta que los resultados muestran una relación positiva entre esta variable y la confianza en la ciencia y la tecnología en Estados Unidos, Japón y Canadá. Pero, por el contrario, los autores no encontraron diferencias significativas en el caso de la Unión Europea (véase tabla 3).

En efecto, como puede apreciarse en la tabla 7, a tenor de los datos del Eurobarómetro de 1992 dedicado monográficamente a la ciencia y la tecnología, las actitudes positivas ante la tecnociencia de los que presentan un alto nivel de alfabetización científica no sobresalen de manera significativa (no existen más de cinco puntos de diferencia, en el mejor de los casos) de las medias registradas en las distintas preguntas. E incluso en los supuestos de las afirmaciones más vinculadas a la cuestión medioambiental, los datos indican una mayor reserva entre quienes poseen un alto nivel de alfabetización tecnocientífica. Con todo, también puede apreciarse que quienes tienen un bajo nivel de alfabetización científica presentan los menores grados de apoyo ante las diversas afirmaciones formuladas a favor de una consideración meliorativa de la tecnociencia. Pero, a mi entender, estos datos no pueden interpretarse sin más como una corroboración por pasiva de este tercer eje de la tesis tradicional, dado que de manera plausible (y así la he detectado en las reuniones de grupo referidas) hay una interpretación alternativa que entiende que en este grupo social concreto se dan a la vez, junto a una menor alfabetización tecnocientífica, situaciones de mayor indefinición, de falta de una posición firme y perfilada, así como de ausencia de interés real ante cuestiones que se encuentran alejadas de los intereses y contextos de su vida cotidiana. Por consiguiente, y como han puesto de manifiesto los distintos estudios (Bauer, Durant y Evans, 1994; Evans y Durant, 1995; Durant y otros, 2000), de esta menor 
TABLA 7

Porcentaje de entrevistados que, según el nivel de alfabetización científica, están muy o bastante de acuerdo sobre las siguientes afirmaciones

Nivel de alfabetización científica

Alto

Medio

Bajo

La ciencia y la tecnología están haciendo que nuestra vida sea más saludable, sencilla y confortable.

Gracias al progreso científico y tecnológico, los recursos naturales de la tierra serán inagotables.

El progreso tecnológico hará posibles altos niveles de consumo y, al mismo tiempo, medios ambientes no contaminados

La ciencia y la tecnología no pueden tener un papel en la mejora del medio ambiente

La aplicación de la ciencia y de las nuevas tecnologías hará más interesante el trabajo.

Gracias a la ciencia y a la tecnología, las generaciones futuras tendrán más oportunidades.

El progreso científico y tecnológico ayudará a curar enfermedades como el sida, cáncer, etc.

Los nuevos descubrimientos siempre encontrarán la forma de neutralizar las consecuencias perjudiciales del desarrollo científico y tecnológico

Las ventajas de la ciencia son mayores que todos los efectos perjudiciales que pueda tener

FUENTE:

Eurobarómetro 38.1 (noviembre 1992).

$\begin{array}{llll}76 & 80 & 75 & 60 \\ 23 & 19 & 28 & 24 \\ 31 & 30 & 34 & 24 \\ 21 & 18 & 26 & 21 \\ 54 & 57 & 55 & 37 \\ 63 & 65 & 64 & 49 \\ 84 & 89 & 81 & 65 \\ & & & \\ 47 & 48 & 51 & 31 \\ 52 & 55 & 25 & \end{array}$

apreciación meliorativa no puede deducirse que un aumento de la alfabetización tecnocientífica, con el consiguiente incremento de la información disponible al respecto, implique necesariamente el crecimiento de las actitudes positivas hacia la ciencia y la tecnología. Más bien lo que sucede es que cuanta más información se dispone sobre la tecnociencia, más incertidumbre y variaciones se producen en las valoraciones que se realizan de la tecnociencia.

Los datos del Eurobarómetro de 2001 también dedicado monográficamente a la tecnociencia, y realizado en los entonces 15 países miembros de la UE con un total de 16.029 entrevistas, confirman en buena medida este mismo escenario de una corroboración débil, y sólo para ciertos aspectos, de este tercer eje de la tesis tradicional. Los datos del documento publicado ${ }^{7}$ por la oficina responsable del Eurobarómetro muestran unos coeficientes

7 Eurobarómetro 55.2. (2001), «Europeans, science and technology», p. 32. 
de correlación entre las respuestas a las distintas preguntas actitudinales y los niveles de alfabetización científica, expresados por el número de aciertos a una batería de trece preguntas sobre contenidos sustantivos de distintos campos científicos (del tipo acertar que la afirmación «los antibióticos destruyen tanto los virus como las bacterias» es falsa, o que "el centro de la Tierra está muy caliente» es correcta), que se encuentran comprendidos en un rango de 0,287 (el mayor, referido a la afirmación de que «la ciencia y la tecnología no pueden tener un papel en la mejora del medio ambiente») y $-0,019$ (negativo o casi cero, y vinculado al ítem «la ciencia y la tecnología resolverán todos los problemas»). El análisis de las distintas puntuaciones obtenidas permite encontrar la existencia de diferentes pautas de relación entre ambas variables.

En primer lugar, cabe destacar que existen una serie de proposiciones referidas al positivo papel de la tecnociencia en la cura de enfermedades $(r$ : 0,244), en la creación de más oportunidades para las generaciones futuras ( $r$ : 0,237), en hacer la vida más saludable, sencilla y confortable $(r: 0,222)$ y en lograr que el trabajo sea más interesante $(r: 0,211)$, que obtienen unos coeficientes de correlación positivos y significativos con el índice de alfabetización científica. Así, y para estos aspectos concretos, puede concluirse que a mayor nivel de alfabetización, más confianza ante la tecnociencia en el conjunto de la Unión Europea. Lo cual corrobora la tesis tradicional. Pero, en segundo lugar, el nivel de alfabetización también mantiene un coeficiente de correlación positivo y significativo (el ya reseñado más alto de todos, r: 0,287) con la afirmación de que la ciencia y la tecnología no pueden tener un papel en la mejora del medio ambiente. Es decir, para este aspecto concreto, un más alto nivel de alfabetización lleva consigo una significativa mayor tendencia a mantener una distancia crítica.

En tercer lugar, la afirmación que expresa la dimensión más general de la ciencia y la tecnología («las ventajas de la ciencia son mayores que todos los efectos perjudiciales»), la que afirma que los nuevos descubrimientos pueden neutralizar las consecuencias perjudiciales del desarrollo científico y la que destaca el papel de la tecnociencia para erradicar la pobreza registran unos coeficientes de correlación todavía positivos ( $r$ : 0,136, r: 0,081 y r: 0,078, respectivamente), pero de escaso valor. De lo que puede inferirse que, contrariamente a lo que sostendría este eje del cognitivismo ilustrado, aquí no existe una base empírica significativa que permita afirmar que a mayor alfabetización, mejor valoración de la tecnociencia. Finalmente, las frases referidas a la capacidad de la ciencia y la tecnología para crear más empleo ( $r: 0,04)$, hacer inagotables los recursos naturales ( $r$ : $-0,0082)$ o resolver todos los problemas ( $r$ : -0,019) presentan niveles de correlación muy bajos y, por tanto, de signo dudoso. Es decir, no son significativos y no permiten concluir siquiera que exista esa relación de dependencia o causalidad entre el sentido positivo de las afirmaciones y los niveles de alfabetización tecnocientífica. 
De otro lado, Bauer, Durant y Evans (1994), con los datos del Eurobarómetro monográfico de 1989, han puesto de manifiesto que las relaciones entre conocimiento y actitudes, al igual que ocurría en lo referente al interés sobre estos temas, son más complejas de lo que el tradicional modelo lineal establece. Aun cuando puede afirmarse que las correlaciones positivas entre conocimiento y actitudes existen, también puede señalarse que son débiles. Además, identificaron una caída de las actitudes positivas entre algunos de los países más desarrollados social, económica, educativa y científicamente (como Alemania o Reino Unido). De otra parte, encontraron que entre quienes tienen más altos niveles de alfabetización aumentaban las valoraciones positivas hacia aquellos aspectos de la ciencia y la tecnología con utilidades inmediatas, mientras que descendía su apoyo en aquellos campos afectados por los debates morales y en la investigación de índole más básica o con menor utilidad inmediata. Todos estos hallazgos también han sido corroborados en el análisis de una encuesta bajo la perspectiva de la comprensión pública de la ciencia y la tecnología acometida en el Reino Unido en 1988 (Evans y Durant, 1995), de tal manera que incluso se ha concluido que el interés hacia estos temas puede ser un predictor más fuerte para dar cuenta de las actitudes positivas ante la tecnociencia que la alfabetización científica.

Por otra parte, Durant, Bauer, Gaskell, Midden, Liakopoulos y Scholten (2000), a partir del análisis de los datos del Eurobarómetro de 1992, han señalado que la variabilidad de los datos actitudinales en los distintos países permite afirmar que la estructuración de los mismos obedece a un lógica más amplia, en la que el factor alfabetización científica no interviene en exclusiva y su impacto sólo alcanza un determinado umbral y en algunos aspectos concretos. Al llevar a cabo estos autores un análisis de correlación parcial, con el fin de controlar los efectos de las variables sociodemográficas, entre la alfabetización científica y una serie de veintitrés frases que expresan la concepción de la tecnociencia ante tres clusters actitudinales (progreso, panacea e impacto en el futuro), resulta que los países más desarrollados o postindustriales de la Unión Europea, que además ostentan unos altos niveles de alfabetización científica (como Gran Bretaña, Holanda, Dinamarca o Alemania -ex RFA-), presentan una relación estadística negativa o la ausencia de relación estadística significativa entre el nivel de alfabetización y las actitudes ante la tecnociencia entendida como progreso. Por el contrario, la relación, aunque débil, es positiva y significativa en Portugal, el país con más bajo nivel (comparativo) de alfabetización tecnocientífica. Es decir, que las asunciones centrales del llamado modelo deficitario se corroboran sólo en algunos de los países menos desarrollados de la Unión Europea.

Su análisis les lleva a interpretar que las relaciones entre actitudes y niveles de alfabetización responden a un modelo caótico, alejado de la relación lineal supuesta, que puede entenderse a partir de un efecto postindustrial por el que las sociedades más avanzadas de la 
Unión Europea han desarrollado unas pautas de asimilación y acomodación ante la ciencia y la tecnología que implican mantener actitudes más alertas y críticas respecto de la relación costes-beneficios que suponen los impactos de las mismas. Así, siguen viendo a la tecnociencia como un factor decisivo para el progreso, pero son pesimistas respecto de hasta qué punto ésta puede resolver los más amplios problemas sociales, y están preocupados sobre el papel de la ciencia y la tecnología en la alteración de las condiciones medioambientales y el mantenimiento de los actuales estilos de vida. Por el contrario, los ciudadanos, especialmente los más instruidos, de aquellos países con menor nivel (relativo) de desarrollo depositan en la tecnociencia muchas de sus esperanzas para alcanzar las cotas de bienestar de sus vecinos más avanzados, de lo que se deriva una decidida apuesta por el papel que la ciencia y la tecnología pueden y deben tener para conseguir dicho objetivo. De ahí la existencia de una consideración tan positiva.

Así pues, la familiaridad con la tecnociencia crea formas evaluativas en las que, a la vez que se reconoce su importancia y relevancia en determinados logros alcanzados en campos como la medicina o el trabajo, que contribuyen decisivamente a permitir una vida de progreso y bienestar, también se generan unas actitudes de cautela, pragmatismo y distancia que asumen sus logros conseguidos pero que, a la vez, consideran sus actuales consecuencias negativas y sus riesgos potenciales de futuro. Lo cual puede llevar, entre otras posibilidades, a un posicionamiento crítico contra cualquier iniciativa que se entienda como legitimadora de una pretendida condición inmaculada de la tecnociencia. Por el contrario, los ciudadanos de los países con un menor nivel de desarrollo, e históricamente con una menor experiencia cotidiana con la tecnociencia, pueden mostrar una mayor indiferencia por ignorancia hacia los temas de ciencia y tecnología, pero también pueden desarrollar una pauta de apuesta optimista para que este factor permita el equiparamiento con aquellas sociedades más avanzadas que, en su entorno, les sirven de referencia.

En suma, los diversos datos hasta aquí aportados resultan algo contradictorios, en la medida que en algunos contextos sociales (países como Estados Unidos o Japón) contribuyen a corroborar la tesis ilustrada que vincula lineal y positivamente actitud y conocimiento, pero en el supuesto del conjunto de la Unión Europea, que aquí he considerado con mayor extensión, los datos sólo permiten sostener esta interpretación para algunos aspectos concretos de la ciencia y la tecnología. Esta diversidad de hallazgos sugiere que no hay un modelo único o estable para identificar la relación entre los niveles de instrucción y alfabetización y las representaciones sociales de la tecnociencia. Y, así, los hallazgos de Durant y otros (2000) son consistentes con la conclusión que extraje de las reuniones de grupo mantenidas, que la valoración meliorativa de la ciencia y la tecnología puede ser tanto por valoración de sus logros como por la sublimación de sus posibilidades. Y, también, que un posicionamiento no positivo puede deberse a un más bajo nivel de alfabetización o instruc- 
ción educativa, pero asimismo a un mejor conocimiento de los resultados concretos, queridos y no queridos, que produce una decidida apuesta, históricamente sostenida, por la industrialización y modernización de un país.

De hecho, del análisis de los discursos de las distintas reuniones de grupo realizadas he podido identificar que la familiaridad y el conocimiento generan una imagen más sólida de la tecnociencia. Imagen que se bifurca en una consideración positiva, de un lado, pero, de otro, también en un juicio más cauteloso, pragmático y ambivalente, cuando no directamente crítico. Sin duda, esta aproximación tiene que vincularse más directamente con variables sociales macro como la estructura socioeconómica o la cultura de una nación. Cuestión ésta que apuntaré con mayor detalle en el siguiente y último epígrafe.

\section{CONTEXTOS Y REPRESENTACIONES SOCIALES ANTE LA TECNOCIENCIA: UN MODELO EXPLICATIVO PLURAL}

En los epígrafes anteriores, con la intención de falsar los ejes nodales de la tesis tradicional de los estudios de la «percepción social de la ciencia y la tecnología», he mostrado el déficit empírico y la insuficiencia teórica de sus principales asunciones para dar cuenta de las representaciones sociales de la tecnociencia en las sociedades contemporáneas avanzadas, con especial atención al caso español y a los datos europeos. Ahora voy a esbozar un modelo alternativo que permita interpretar el conjunto de datos aportados e integrarlos en un modelo, basado en los principios epistemológicos y metodológicos de la heterogeneidad y el pluralismo, que pueda dar cuenta de la realidad social con un mayor grado de verosimilitud. Asumir ambos principios implica desarrollar tres operaciones de manera concurrente: identificar los distintos niveles de esa realidad social que, como en otras parcelas, se configura acorde al principio de realidades múltiples; buscar las variables presentes en cada nivel y que pueden obedecer a lógicas distintas, de ahí la idea del pluralismo cognitivo y metodológico; y establecer las formas en que se articulan entre sí los distintos niveles que conforman el fenómeno objeto de análisis.

En nuestro caso, esta propuesta supone esbozar un modelo sobre tres niveles: el primero, al que califico como subyacente, está conformado por las distintas formas psicosociales en las que pueden configurarse las representaciones sociales de la tecnociencia. Como indiqué anteriormente, en mi opinión, éstas no se configuran de un modo dicotómico entre dos polos (positivo vs. negativo), sino a lo largo de un continuum en el que estos dos puntos constituyen los extremos. En este sentido, asumo lo que Pardo y Calvo (2001) sugieren respecto de la fragmentación de actitudes en diferentes clusters en función del impacto que en las mismas tienen los distintos tipos de áreas y resultados de la tecnociencia. Im- 
pactos que dan lugar a que las relaciones entre ambas variables no sean lineales, sino cambiantes y complejas. Pero también entiendo que la diversidad de distintas posiciones a lo largo de dicho continuum, y la inestabilidad de muchas de ellas, refuerzan la emergencia de las representaciones sociales ambivalentes sobre la dualidad (positiva vs. negativa) que los impactos concretos de la ciencia y la tecnología han generado a lo largo del tiempo. Además, esta ambivalencia ha aumentado conforme la tecnociencia alcanzaba la posición central que tiene en las actuales sociedades del conocimiento, dado que, por su naturaleza, este tipo de sociedades mantienen una simultánea dependencia y exigencia respecto de los resultados tecnocientíficos (Torres, 2005).

En la conformación de estas representaciones sociales están presentes todos los elementos identificados por Moscovici (1984). Así, el campo de representación está formado por las distintas evaluaciones que se realizan de las diversas aplicaciones de la ciencia y la tecnología, lo que da lugar al referido continuum de posibles actitudes positivas vs. negativas. Pero, en mi opinión, en las sociedades contemporáneas avanzadas la ambivalencia conforma, y cada vez con mayor intensidad, el núcleo de dicho campo de representación, dada la central dependencia que estas sociedades tienen de la tecnociencia y la naturaleza dual de sus actividades y resultados concretos (progreso, abundancia y bienestar vs. posibilidad de alterar el ciclo natural de la vida y la naturaleza). En todo caso, mediante este núcleo figurativo se simplifica en una imagen concreta la representación social de la tecnociencia y, con ello, se reduce la complejidad que implica considerar tanto las distintas esferas de la ciencia y la tecnología con sus diversos tipos de impactos y consecuencias, y la abstracción de sus contenidos conceptuales, como las múltiples y paralelas operaciones que suponen un modelo permanente de evaluación de sus costes-beneficios. Una vez naturalizada y objetivada esta representación, la información suministrada va a seleccionarse e integrarse en un proceso constante de reconstrucción selectiva. De ahí que, en las sociedades avanzadas, el aumento de la información (otro de los elementos señalados por Moscovici) sobre la ciencia y la tecnología en general, y de la alfabetización tecnocientífica en particular, no suponga necesariamente un incremento de las actitudes positivas, sino más bien el refuerzo de las representaciones ambivalentes.

El segundo nivel del modelo, al que llamo estructurante, agrupa a los distintos tipos de sociedad y estructuras sociales. La importancia de su papel radica en que estas variables favorecen la concreción de los factores subyacentes en un sentido u otro, y con una mayor o menor intensidad. En este sentido, vuelvo aquí a recurrir a las tesis del efecto postindustrial y las variantes nacionales perfiladas por Durant y otros (2000), que han abierto un nuevo espacio para pensar las formas en que se articula actualmente la cultura tecnocientífica en las sociedades avanzadas contemporáneas. No obstante, estoy de acuerdo con Pardo y Calvo (2001: 188) en que se trata más de un programa de investigación que de un corpus 
sólido de hallazgos empíricos perfectamente contrastados, aun cuando el valor heurístico de sus argumentos ha contribuido a renovar las asunciones habituales de la comprensión pública de la tecnociencia y, por ello, les ha otorgado un amplio crédito entre los estudiosos de este campo.

En concreto, Durant y otros (2000) han distinguido dos tipos de sociedades en Europa, las industriales y las postindustriales, para dar cuenta de las distintas formas de conocer, interesarse y evaluar la ciencia y la tecnología en las sociedades europeas. Sus distintos niveles de desarrollo e industrialización han generado unas bases bien distintas para conformar dos modos de entender las relaciones que se establecen entre la opinión pública y la tecnociencia. Así, de un lado, tenemos las llamadas sociedades industriales (serían los países menos desarrollados de la Unión Europea), en las que el conocimiento tecnocientífico se confina a una élite social con altos niveles sociales, económicos y educativos. En este caso, los criterios sociodemográficos que el deficit model supone (educación, alfabetización científica, etc.) explican en buena medida el interés y actitudes ante estos temas. Así, y al hilo del anterior punto, los factores socioeconómicos juegan un amplio papel a la hora de determinar la distribución del conocimiento científico y tecnológico. En estas sociedades, el interés, al menos el retórico, en la tecnociencia como símbolo del progreso económico e industrial es relativamente alto en todos los sectores de la sociedad. De otro lado, hay un canon relativamente unificado del conocimiento científico y de las tecnologías popularizadas, y, finalmente, existe una correlación positiva, tal y como sostiene la tesis tradicional, entre el nivel de instrucción y alfabetización científicas y el apoyo y valoración positivos de la impronta tecnocientífica.

El corolario de este primer tipo de sociedades, en las que la tecnociencia ha alcanzado sólo una penetración limitada, es que la representación social de la ciencia y la tecnología se encuentra intensiva y extensivamente idealizada, dado que se la considera como la única posibilidad de alcanzar la senda del progreso social y económico.

Por el contrario, en las últimas décadas del siglo xx comenzó a vislumbrarse de manera nítida un segundo tipo de sociedades más avanzadas y sofisticadas en nuestro entorno. Es lo que Durant y otros (2000) llaman sociedades postindustriales, aun cuando con más razón podrían calificarse como sociedades de ciencia o de conocimiento (Lamo de Espinosa, 1996). En este tipo de sociedades, la plasmación de las representaciones sociales de la tecnociencia pasa por el hecho de que el conocimiento tecnocientífico está ampliamente popularizado en la sociedad, es decir, alcanza a amplios segmentos del conjunto de la ciudadanía. Al hilo de lo anterior, los factores sociodemográficos y educativos juegan una parte relativamente pequeña en la determinación de la distribución del interés y la valoración de la ciencia y la tecnología. Frente a lo que ocurría en las sociedades industriales, aquí el 
interés declarado por la tecnociencia es relativamente bajo. Con ello la tecnociencia se da en general por supuesta y, por tanto, hay una proliferación en el dominio público de conocimientos especializados. Finalmente, y como ya hemos indicado, la relación entre conocimiento y apoyo a la ciencia y la tecnología no sólo no es lineal y positiva, como en las sociedades industriales, sino que llega a ser caótica puesto que diferentes segmentos de la sociedad desarrollan diversos puntos de vista sobre las numerosas cuestiones particulares del amplio campo de la tecnociencia.

La conclusión que se obtiene es que en este tipo de sociedades la tecnociencia ya ha conseguido un alto nivel de penetración y, con ello, constituye no sólo una posibilidad idealizada, sino también una realidad que es sometida a una evaluación crítica continua por un público que espera obtener continuos beneficios, a la vez que cada vez está más alerta sobre la posibilidad de encontrar, a través de sus actividades y repercusiones, problemas y perjuicios en casos y aspectos puntuales.

Sobre esta tesis de los dos distintos tipos de sociedad (industrial vs. postindustrial), Durant y otros (2000) añaden una segunda dimensión a su modelo al establecer que las desviaciones del mismo se deben a las circunstancias específicas de cada nación, es decir, a sus peculiaridades locales y a su diferente plasmación histórica. A mi modo de ver, esta sugerencia debe remitir al conjunto cultural que conforman los valores, normas y hábitos con los que cada sociedad ha entendido y contextualizado el conjunto de prácticas científicas y técnicas. En mi opinión, esto permite que distingamos distintos tipos de sociedades en función del papel que la ciencia y la tecnología han jugado en las mismas a lo largo de su historia. Así, por ejemplo, de un lado, se encuentran las de tradición protestante del centro y norte de Europa, en las que la afinidad del temperamento entre el puritanismo y el ethos científico contribuyó a la aceleración de las actividades científicas y tecnológicas y a su definitiva institucionalización y profesionalización (Merton, 1984). De otro, pueden considerarse algunas de las sociedades meridionales europeas, como la española, que cuentan con un largo periodo histórico en el que han vivido distanciadas, cuando no de espaldas, a la poderosa fuerza innovadora que implica el vector tecnocientífico. En todo caso, avanzar en el bosquejo de esta línea de análisis requiere la puesta a punto de estudios de casos que aborden la configuración de las posibles diversas culturas nacionales ante el hecho tecnocientífico.

A este segundo nivel en el que se forman las representaciones sociales de la tecnociencia, formado por los distintos tipos de estructura socioeconómica y las variantes culturales que presenta cada sociedad en particular, puede atribuírsele un nivel estructurante dentro del modelo aquí esbozado, dado que desencadena la cristalización de las distintas representaciones subyacentes de la tecnociencia, así como modula la intensidad de las mismas. Aquí 
radica la fuente social que alimenta la emergencia y centralidad de la ambivalencia de las representaciones sociales de la tecnociencia en las contemporáneas sociedades del conocimiento (Torres, 2005). Amén de que este nivel también fija los límites del espacio y de la lógica interactiva con la que se mueven los actores sociales. Agentes e interacciones que constituyen el tercer nivel del modelo.

Este tercer y último nivel, al que califico de contingente, aglutina las dinámicas de la opinión pública generadas por las estrategias interactivas de comunicación de los distintos actores sociales vinculados a la cuestión que nos ocupa. Al respecto, las reflexiones generadas están menos depuradas y deben tomarse en un sentido más referencial, de marcar un camino para indagaciones futuras. Exploraciones que, además, también deben asumir la limitación que se deriva de la acotación empírica que suponen los estudios de casos, de naturaleza mucho más microsociológica.

En todo caso, estas interacciones pueden entenderse como un sistema de comunicación (Neidhart, 1993) constituido en torno a la que podríamos llamar sus cuatro esquinas, en las que se encuentran los propios científicos y tecnólogos, los políticos y gestores de la tecnociencia, los prescriptores de la opinión pública a través de los medios de comunicación de masas y, finalmente, la audiencia. A su vez, en esta última pueden identificarse varios grados de atención hacia el fenómeno de la tecnociencia, desde el público no atento al atento, pasando por el interesado, tal como han puesto de manifiesto los distintos estudios iniciados por J. D. Miller (Miller, Pardo y Niwa, 1998). Todo lo cual también implicará un tipo, en alguna medida diferente, de actitudes, valoraciones y representaciones sociales. Aquí, por ejemplo, puede integrarse lo que Durant et al. (2000: 148) refieren para tratar de explicar las diferencias entre dos países de desarrollo similar, Alemania y Dinamarca. Aunque ambos confían en el progreso asociado a la tecnociencia, muestran actitudes bien distintas respecto de los impactos futuros de la ciencia y la tecnología en la sociedad (bajo pesimismo en Dinamarca y alto en Alemania). Para los autores, estas diferencias sugieren la importancia que tienen las relaciones de construcción de confianza entre las instituciones científicas y la opinión pública a través de la participación e integración del público en el proceso de toma de decisiones. Y, así, mientras que en Dinamarca se ha seguido más un modelo de participación pública y se ha buscado el compromiso a través de conferencias de consenso y los debates de controversias, en Alemania el proceso ha implicado una baja institucionalización del compromiso público, cuando no el conflicto abierto. Otro ejemplo interesante lo ha aportado Bauer (2000) a partir de un estudio sobre cómo la prensa británica ha tratado los temas de ciencia y tecnología entre 1946 y 1990. Los resultados muestran que a la par que descendía el número de argumentos a favor de los beneficios de la tecnociencia, crecían sobremanera los que combinan una relación evaluadora entre beneficios y riesgos. Además, en los últimos años, en consonancia con 
la extensión de la idea de Beck de la sociedad del riesgo, también han aumentado de manera muy significativa las noticias y argumentos que acentúan la dimensión del riesgo vinculado a algunas de las aplicaciones tecnocientíficas. Dado que el libro de Beck se tradujo al inglés en 1992, y la cada vez más estrecha conexión entre algunos lenguajes sociológicos y los argumentos que manejan los actores sociales, parece plausible que esta última tendencia se habrá intensificado en la última década del pasado siglo, no contemplada en el referido estudio.

Así pues, estimo que esta dinámica de las cuatro esquinas opera, dentro de los grados de libertad que permiten los factores subyacentes y estructurantes arriba mencionados, no sólo por la lógica situacional de intereses que son generados y asumidos por cada uno de los colectivos en cuestión en cada momento, sino también por las pautas y hábitos interactivos que se van conformando con el paso del tiempo, y que afectan a la manera en que los agentes sociales conceptualizan el fenómeno, articulan sus intereses y concretan sus representaciones. $Y$ aquí considero que tienen una consideración relevante, tanto en la conformación de dichas pautas como en la orientación de las acciones sociales presentes, las dinámicas culturales que cada nación en particular ha ido generando a lo largo de su historia. Valga como sugerencia para pesquisas de futuro que tratemos de responder a la pregunta de en qué medida el lema «ique inventen ellos!», como respuesta al célebre artículo de Masson de Morvillers en la Enciclopedia (García Camarero y García Camarero, 1970), ha condicionado por activa o pasiva la variante cultural con la que la sociedad española se ha posicionando ante la ciencia y la tecnología en el pasado, y el papel que pudiera tener en las formas que adopta su representación social en el momento presente.

En definitiva, dar cuenta del contexto social e histórico y asumir que la opinión pública es un ente activo que construye sus representaciones sociales sobre la ciencia y la tecnología son los ejes heurísticos que inspiran el modelo arriba sugerido y que, en mi opinión, dado el notable déficit teórico y empírico de la tesis tradicional y la diversidad de hallazgos registrados en las distintas encuestas acometidas, son los más fértiles principios para llevar a cabo la tarea de remozar el campo dedicado al estudio de la cultura tecnocientífica en las sociedades avanzadas contemporáneas. 


\section{BIBLIOGRAFÍA}

BAUER, M. (2000): «"Science in the Media” as a cultural indicator: contextualizing surveys with media analysis», en Meinolf Dierkes y Claudia von Grote, op. cit.

BAUER, M.; DURANT, J., y EVANS, G. (1994): «European public perception of science», International Journal of Public Opinion Research, vol. 6, n. ${ }^{\circ}$ 2: 163-186.

BEN-DAVID, J. (1964): «Scientific growth: A sociological view», Minerva, vol. 3: 455-476.

BLANCO, J. R., e IRANZO, J. M. (2000): «Ambivalencia e incertidumbre en las relaciones entre ciencia y sociedad», Papers, n. ${ }^{\circ}$ 61: 89-112.

CLARK, H. H., y SCHOBER, M. F. (1992): «Asking questions and influencing answers», en J. M. Tanur (ed.), Questions about questions. Inquiries into the cognitive bases of surveys, New York, Russell Sage Foundation.

DIERKES, M., y GROTE, C. von (eds.) (2000): Between understanding and trust. The public, science and technology, Amsterdam, Harwood Academic Publishers.

DURANT, J. (1992): «What is scientific literacy?», en J. Durant y J. Gregory (eds.), Science and culture in Europe, Londres, Science Museum.

DURANT, J.; BAUER, M.; GASKELL, G.; MIDDEN, C.; LIAKOPOULOS, M., y SCHOLTEN, L. (2000): «Two cultures of public understanding of science and technology in Europe», en Meinolf Dierkes y Claudia von Grote, op. cit.

DURKHEIM, E. (1898): «Représentations individuelles et représentations collectives «, Revue de Métaphysique et de Morales, tomo VI (mai): 273-300. (También reproducido en E. Durkheim, Sociología y filosofía, Madrid, Miño y Dávila editores, 2000.)

EUROBARÓMETROS, n. ${ }^{\text {os }} 31$ (1989), 38.1 (1992), 55.2 (2001) y 63.1 (2005): «Public understanding and attitudes in science and technology in Europe». http://europa.eu.int/comm/public_opinion/index_en.htm.

ETZIONI, A., y NUNN, C. (1974): «The public appreciation of science in contemporary America», Daedalus, vol. 3, n. ${ }^{\circ}$ 3: 195-205.

EVANS, G., y DURANT, J. (1995): «The relationship between knowledge and attitudes in the public understanding of science in Britain», Public Understanding of Science, vol. 4: 57-74.

FECYT (2005): Percepción social de la ciencia y la tecnología en España, Madrid, FECYT.

GARCÍA CAMARERO, Ernesto, y GARCÍA CAMARERO, Enrique (1970): La polémica de la ciencia española, Madrid, Alianza Editorial.

GARCÍA FERRANDO, M. (1987): «Imagen de la ciencia y la tecnología en España», REIS, n 37: 139-172.

GODIN, B., y GINGRAS, Y. (2000): «What is scientific and technological culture and how is it measured? A multidimensional model», Public Understanding of Science, vol. 9: 43-58.

GONZÁLEZ BLASCO, P. (1993): «Actitudes sociales ante la ciencia y la tecnología», RIS, n. ${ }^{\circ}$ 4: 233-270.

GROSS, A. G. (1994): «The roles of rhetoric in the public understanding of science», Public Understanding of Science, vol. 3: 3-23.

IBÁÑEZ GARCÍA, T. (1988): Ideologías de la vida cotidiana, Barcelona, Sendai.

LAMO DE ESPINOSA, E. (1996), Sociedades de cultura, sociedades de ciencia, Oviedo, Nóbel. 
MERTON, R. K. (1984): Ciencia, tecnología y sociedad en la Inglaterra del siglo XVII, Madrid, Alianza Editorial.

MILLER, J. D.; PARDO, R., y NIWA, F. (1998): Percepciones del público ante la ciencia y la tecnología. Estudio comparativo de la Unión Europea, Estados Unidos, Japón y Canadá, Madrid, Fundación BBV.

MILLER, S. (2001): «Public understanding of science at the crossroads», Public Understanding of Science, vol. 10: 115-120.

MOSCOVICI, S. (1984): «The phenomenon of social representations», en F. Farr y S. Moscovici (eds.), Social representations, Cambridge, Cambridge University Press, pp. 3-69.

NEIDHART, F. (1993): «The public as a communication system», Public Understanding of Science, vol. 2: $339-350$.

PARDO, R. (2001): “La cultura científico-tecnológica de las sociedades de modernidad tardía», en M. Ángeles Durán et al., Estructura y cambio social. Libro homenaje a Salustiano del Campo, Madrid, CIS, pp. 1077-1108.

PARDO, R., y CALVO, F. (2002): «Attitudes toward science among the european public: a methodological analysis», Public Understanding of Science, vol. 11, n. ${ }^{\circ} 2: 155-195$.

TORRES, C. (2005): «La ambivalencia ante la ciencia y la tecnología», RIS, n. ${ }^{\circ} 42$. 